\title{
Laser-based trace gas detection of ethane as a result of photo-oxidative damage in chilled cucumber leaves (invited)
}

\author{
I. E. Santosa and L. J. J. Laarhoven \\ Department of Molecular and Laser Physics, University of Nijmegen, Nijmegen, The Netherlands \\ J. Harbinson \\ Horticultural Production Chains Group, Wageningen University, Wageningen, The Netherlands \\ S. Driscoll \\ Crop Performance and Improvement Division, IACR-Rothampsted, Harpenden, United Kingdom \\ F. J. M. Harren \\ Department of Molecular and Laser Physics, University of Nijmegen, Nijmegen, The Netherlands
}

(Presented on 26 June 2002)

\begin{abstract}
At low temperatures, high light intensity induces strong photooxidative lipid peroxidation in chilling sensitive cucumber leaves. A sensitive laser-based photoacoustic detector was employed to monitor on-line the evolution of ethane, one of the end products of lipid peroxidation. The $\Delta v=2 \mathrm{CO}$ laser operated in the 2.62-4.06 $\mu \mathrm{m}$ infrared wavelength region with a maximum intracavity power of 11 W. In combination with an intracavity placed photoacoustic cell the laser was able to detect ethane down to 0.5 part per billion. Cucumber leaf disks chilled in the light produce ethane; the rate of ethane production depends on the applied temperature, light intensity, and period of chilling. (C) 2003 American Institute of Physics. [DOI: 10.1063/1.1512772]
\end{abstract}

\section{INTRODUCTION}

For most tropical and subtropical plants low temperature is unfavorable as it affects growth and development and limits their ability to survive. Cold stress is for farmers the third cause of crop loss after drought and excess of water. ${ }^{1}$ Injury is found on chilling-sensitive plants when they are kept at low temperatures $\left(<5^{\circ} \mathrm{C}\right)$ in light conditions. ${ }^{2}$ Such visible leaf injury is due to damage to the cells, which in turn is caused by electrolyte leakage of the cell membranes. This damage is associated with the presence of free radicals. ${ }^{3}$ Low temperatures slow down the electron transport chains and inhibit alternative energy dissipation paths; ${ }^{4}$ both factors enhance the formation of free radicals at low temperatures. Furthermore, low temperatures also decrease the activity of antioxidants and when the balance between antioxidants and free radicals is disturbed peroxidation of the lipid membrane occurs. Free radicals attack the polyunsaturated fatty acid chains of the membrane lipids. ${ }^{5}$ Various studies related to peroxidation of lipids during chilling have been performed by investigating the presence of free radicals and by directly measuring the effect of lipid peroxidation. This is usually accomplished by measuring the concentrations of end products, e.g., malondialdehyde and ethane. Determination of malondialdehyde content requires tissue extraction, ethane can be measured nondestructively. In the past, a gas chromatograph was applied in most of the ethane measurements. However, its slow response precludes monitoring of fast processes such as the effect of rewarming of chilled samples. The present study investigates ethane evolution in chilled and postchilled cucumber leaves under light exposure. For the detection of ethane a $\mathrm{CO}$ laser generating infrared light in the 2.62-4.06 $\mu \mathrm{m}$ wavelength range was developed and combined with photoacoustic detection. With this system ethane evolution was followed on-line at a part per billion detection level.

Since the realization of the first CO laser in $1965,{ }^{6}$ this radiation source has been developed and applied for various purposes. Its high output power makes the $\mathrm{CO}$ laser a good candidate for industrial application next to $\mathrm{CO}_{2}$ lasers. For spectroscopic applications, the spectral emission lines of the CO laser overlap with a large number of absorption lines of relevant organic and inorganic compounds. Therefore CO lasers in conjunction with photoacoustic cells have been employed to monitor trace gases. ${ }^{7-12}$ The $\mathrm{CO}$ laser emission covers the spectral region from 4.6 to $8.2 \mu \mathrm{m}(v=1 \leftarrow 2$ to the $v=35 \leftarrow 36$ band) providing intracavity laser powers up to $40 \mathrm{~W}^{7,8}$ To extend the number of accessible gases the wavelength region of the $\mathrm{CO}$ laser has been expanded (2.62$4.06 \mu \mathrm{m})$ using the first overtone $(\Delta v=2)$ mode. Strong absorptions of hydrocarbons like methane, ethane, and pentane are found in this wavelength region. The operation of the first $\mathrm{cw}$ overtone $\mathrm{CO}$ laser of this kind was reported in 1989. ${ }^{13}$ Subsequent development has led to enhanced output powers, more laser lines and, hence, the coverage of a wider wavelength region. ${ }^{14}$

\section{LASER BASED ETHANE DETECTION}

The construction of the $\Delta v=2 \mathrm{CO}$ laser presented here is based on previous developments (Fig. 1), ${ }^{8}$ it consists of a resonator and liquid nitrogen cooled discharge tube. A Littrow mounted grating (425 lines $/ \mathrm{mm}$, blaze angle 2.8-4.0 $\mu \mathrm{m})$ and a high reflection (100\%) mirror (radius of curvature $4 \mathrm{~m}$ ) each at one end define the laser resonator. The resonator length is optimized using a piezo crystal. The laser power is 


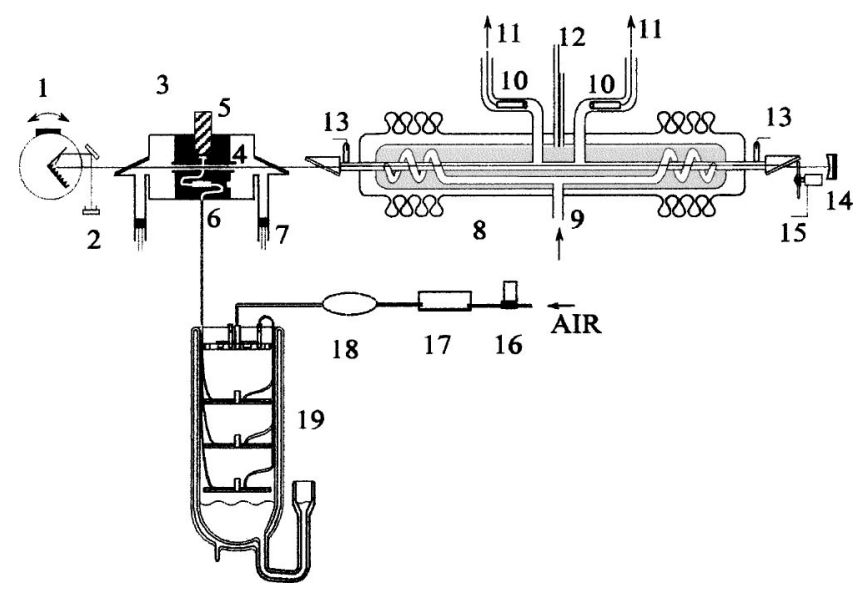

FIG. 1. Experimental setup used for CO laser photoacoustic detection. 1, grating; 2, power meter; 3 , intracavity photoacoustic cell; 4 , resonator tube; 5 , microphone; 6 , inlet for trace gases; 7 , adjustable plungers to minimize window signal; 8, discharge tube; 9, gas mixture inlet; 10, cathode; 11, gas mixture outlets; 12, liquid nitrogen cooling inlet/outlet; 13, anode; 14, end mirror; 15, chopper; 16; flow controller; 17, sample cuvette; 18, scrubber; and 19 , cooling trap.

measured via the zeroth order reflection of the grating by a pyroelectric detector. This $\mathrm{CO}$ overtone laser generates 20 vibrational bands (15P to 34P) and 127 laser lines distributed over 3-8 laser lines per band with a maximum intracavity power of $11 \mathrm{~W}$.

The photoacoustic cell is placed inside the cavity of the $\mathrm{CO}$ laser to achieve a high effective laser power. The cell is an acoustical resonator $150 \mathrm{~mm}$ long and $15 \mathrm{~mm}$ in diameter, connected to buffer volumes which are closed with $\mathrm{ZnSe}$ windows mounted at Brewster angle. This configuration yields a resonance frequency of $1090 \mathrm{~Hz}$ in air (at $1 \mathrm{~atm}$ pressure), and a quality factor of 38 . The gas inlet and the microphone are located in the middle of the photoacoustic cell, the outlets are in the buffer volumes. The photoacoustic signal is monitored by an electret microphone (Knowless EK 3024) and amplified via a lock-in amplifier. To reduce the noise, the gas inlet is connected to the cell via an acoustic damper. Furthermore, adjustable plungers are added to the buffer volumes to suppress the signal generated at the $\mathrm{ZnSe}$ windows.

For the fundamental $\mathrm{CO}$ laser transitions in the wavelength range of 4.6-8.2 $\mu \mathrm{m}$, the absorption coefficients of various gases, e.g., for acetaldehyde, ethanol, $\mathrm{H}_{2} \mathrm{O}$, and $\mathrm{CO}_{2}$ have been determined. ${ }^{12}$ In the overtone $\mathrm{CO}$ laser region $(2.62-4.06 \mu \mathrm{m})$ so far only a single attempt has been made to determine the concentration of gases. ${ }^{10}$ With the present setup, and using a $75 \mathrm{~cm}$ long absorption cell extra cavity, absorption spectra for ethane, pentane, and ethylene have been determined. ${ }^{15}$ Here, only the absorption coefficients of these gases at the relevant laser lines are shown (Table I). The detection limits (signal-to-noise ratio $=1$ ) for ethane, pentane, and ethylene are $0.5,0.5$, and $5 \mathrm{ppb}$, respectively. The distinct fingerprints of these gases allow concentration measurements in multicomponent mixtures. The selectivity is obtained by choosing the best set of laser lines to minimize interference. ${ }^{16,17}$
TABLE I. Selected laser lines and absorption coefficients (in atm ${ }^{-1} \mathrm{~cm}^{-1}$ ) of ethane, ethylene, and pentane. The latter two are relevant because they interfere with detecting ethane.

\begin{tabular}{ccccc}
\hline \hline $\begin{array}{c}\text { Laser } \\
\text { line }\end{array}$ & $\begin{array}{c}\text { Wave number } \\
\left(\mathrm{cm}^{-1}\right)\end{array}$ & $\begin{array}{c}\text { Ethane } \\
\left(\mathrm{atm}^{-1} \mathrm{~cm}^{-1}\right)\end{array}$ & $\begin{array}{c}\text { Pentane } \\
\left(\mathrm{atm}^{-1} \mathrm{~cm}^{-1}\right)\end{array}$ & $\begin{array}{c}\text { Ethylene } \\
\left(\mathrm{atm}^{-1} \mathrm{~cm}^{-1}\right)\end{array}$ \\
\hline $\mathrm{v}^{2} \mathrm{P}_{10}$ & 3097.76 & $0.19 \pm 0.01$ & $0.109 \pm 0.006$ & $0.21 \pm 0.01$ \\
$\mathrm{v}_{24 P_{8}}$ & 3007.30 & $9.0 \pm 0.7$ & $0.53 \pm 0.04$ & $0.18 \pm 0.02$ \\
$\mathrm{v}_{24} \mathrm{P}_{13}$ & 2988.38 & $5.2 \pm 0.5$ & $3.2 \pm 0.6$ & $1.9 \pm 0.2$ \\
$\mathrm{v}^{25 P}$ & 2954.94 & $9.4 \pm 0.9$ & $7.7 \pm 0.7$ & $0.15 \pm 0.02$ \\
\hline \hline
\end{tabular}

\section{A. Ethane detection from chilled plants}

Gases were measured as they were released from chilled leaves of 25 day old cucumber plants, under varying light intensity and temperature conditions. The leaves were placed in a specially designed cuvette made from annealed brass and covered by a glass plate. It has a small volume-tosurface area ratio (diameter $15 \mathrm{~cm}$, depth $0.5 \mathrm{~cm}$ ) in order to minimize dilution effects, while a substantial surface area enables the study of a large leaf. The cuvette is cooled by flowing (temperature-controlled) water from a chiller. Because of its high heat capacity and its thermal isolation from the surroundings, the temperature inside the cuvette was constant within $0.5^{\circ} \mathrm{C}$, as monitored with a temperature sensor. The light source used for illumination of the leaf sample consists of an array of 320 red LEDs, mounted on a printed circuit board covering a $8 \times 10 \mathrm{~cm}^{2}$ area. This light source provides a high intensity (up to $600 \mu \mathrm{mol} \mathrm{s}{ }^{-1} \mathrm{~m}^{-2}$ ) of monochromatic light $(\lambda=650 \mathrm{~nm})$. A change of intensity can be achieved simply by varying the current without shifting of the peak wavelength or any additional heating effect.

During measurement, a leaf was flushed continuously by a flow of hydrocarbon-free, clean air, containing approximately $300 \mathrm{ppm} \mathrm{CO}_{2}$, the flow rate was kept at $1.5 \mathrm{l} / \mathrm{h}$. Behind the cuvette the flow was split, the first part of $1.0 \mathrm{l} / \mathrm{h}$ was used to measure ethane in the photoacoustic cell, and the second part of $0.5 \mathrm{l} / \mathrm{h}$ was directed to an infrared gas analyzer (URAS 10E, Hartmann \& Braun AG Frankfurt am Main) for measuring the $\mathrm{CO}_{2}$ concentrations. To eliminate the effect of interfering gases the carrier gas was led through a set of scrubbers and a cooling trap before entering the photoacoustic cell. ${ }^{12}$

\section{Effect of low temperature and constant light intensity}

Ethane concentrations in the gas flow from the leaf were monitored continuously at 2,10 , and $21^{\circ} \mathrm{C}$. Irrespective of temperature, no ethane was observed from chilled cucumber leaves in the dark. Chilled cucumber leaves under light conditions at $2{ }^{\circ} \mathrm{C}$ produced significantly more ethane than the nonchilled samples (Fig. 2). During the first hours of treatment no ethane was detected, but after a prolonged exposure to cold and light the ethane level increased. A similar behavior was found for leaves treated at 10 and $21^{\circ} \mathrm{C}$ but at these higher temperatures the onset of release was delayed and both the rate of increase and the final level were lower. 


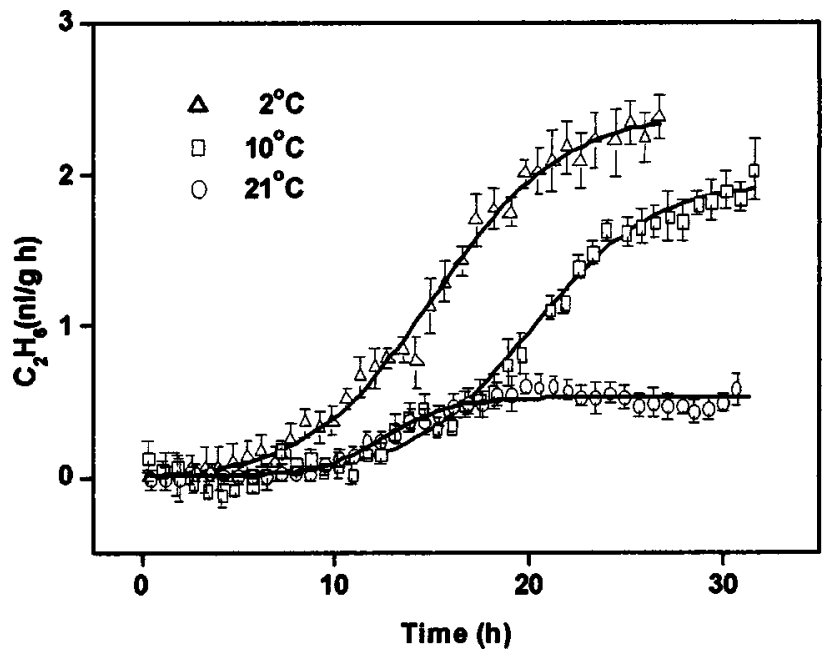

FIG. 2. Effect of temperature on ethane evolution. At $0^{\mathrm{h}}$ the leaves were transferred from $21^{\circ} \mathrm{C}$ to: $2{ }^{\circ} \mathrm{C}(\triangle), 10^{\circ} \mathrm{C}(\square)$, or $21^{\circ} \mathrm{C}(\bigcirc)$ under 500 $\mu \mathrm{mol} \mathrm{s}{ }^{-1} \mathrm{~m}^{-2}$ light intensity. Data points $( \pm \mathrm{SD})$ are background corrected and averaged over 12 measurement points.

\section{Effect of varying the light intensity}

For this experiment the leaf was kept at $2{ }^{\circ} \mathrm{C}$ and under light for 1 day, ethane production was stable then. The effect of switching the light off and on is shown in Fig. 3. Thanks to the on-line response of the system it could be observed that as soon as the light was off ethane emission dropped; the light on-off response in ethane production is virtually instantaneous. When the light intensity was changed gradually, from $570 \mu \mathrm{mol} \mathrm{s}^{-1} \mathrm{~m}^{-2}$ to 0 and back at a constant temperature of $2{ }^{\circ} \mathrm{C}$, irrespective of the direction of change in the light intensity, increasing or decreasing, the ethane production had a linear relation with the light intensity.

\section{Effect of temperature change}

To investigate postchilling effects, an illuminated-chilled leaf was exposed directly to room temperature $\left(21^{\circ} \mathrm{C}\right)$, under constant light intensity. A sudden increase in the ethane pro-

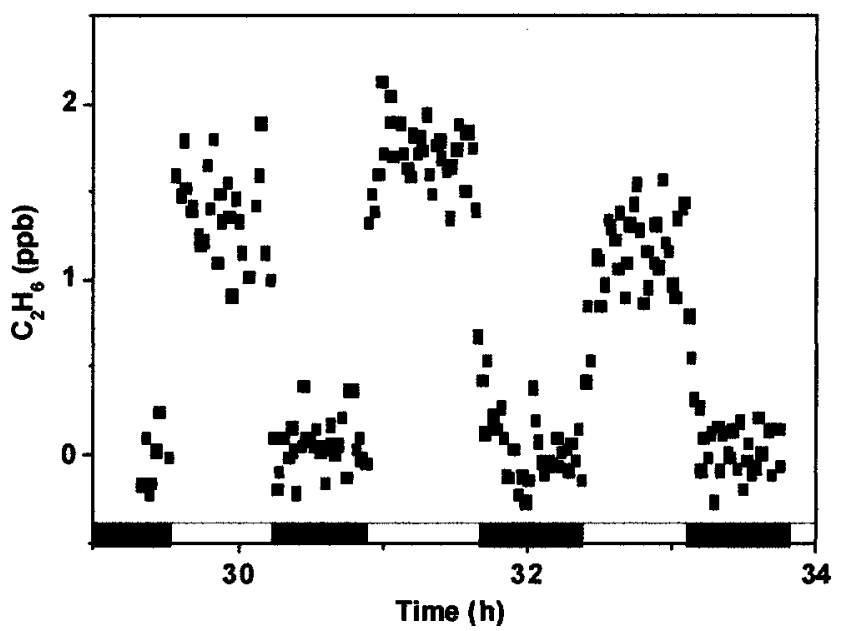

FIG. 3. Effect of light on ethane evolution. Starting at $0^{\text {h }}$ the leaf was exposed to $2{ }^{\circ} \mathrm{C}$ under $500 \mu \mathrm{mol} \mathrm{s}{ }^{-1} \mathrm{~m}^{-2}$ light intensity. When the production rate of ethane was virtually constant (after $24 \mathrm{~h}$ ), the light was switched off and on. The on/off light conditions are indicated by the bar at the bottom of the figure.

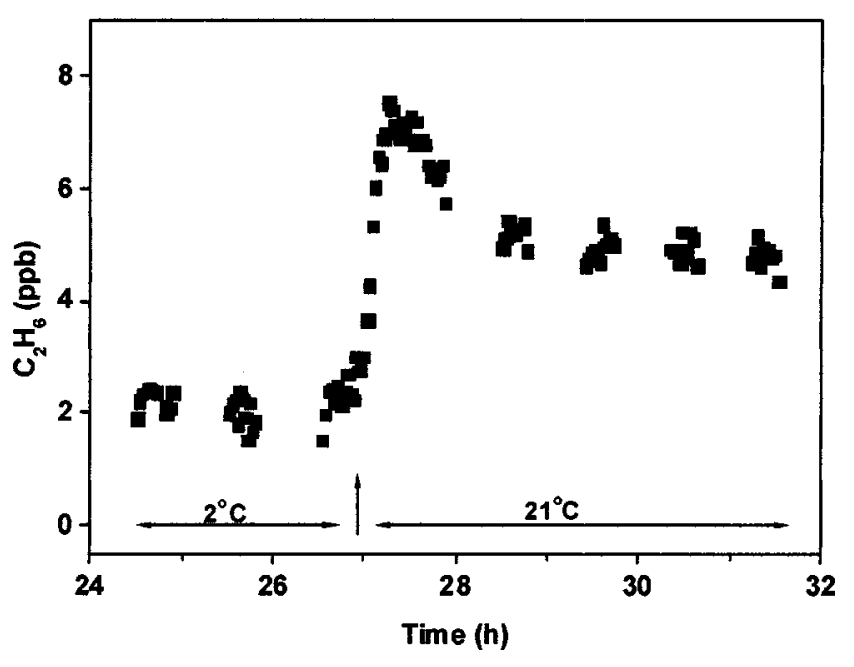

FIG. 4. Postchilling effect on the ethane evolution under constant light intensity. At $0^{\mathrm{h}}$ the leaf was exposed to $2^{\circ} \mathrm{C}$ under $570 \mu \mathrm{mol} \mathrm{s}{ }^{-1} \mathrm{~m}^{-2}$ light intensity. After $27 \mathrm{~h}$ of constant light at $2{ }^{\circ} \mathrm{C}$ the temperature was raised in one step to $21^{\circ} \mathrm{C}$ as indicated by the arrow.

duction was detected with subsequent decrease to a constant level (Fig. 4). The overshoot in ethane lasted about $90 \mathrm{~min}$. After that the level of the ethane production in the postchilling remained significantly higher than that observed during the chilling period. When an illuminated-chilled leaf was transferred directly to room temperature $\left(21^{\circ} \mathrm{C}\right)$ and simultaneously exposed to dark conditions, only a transient dip of ethane production was detected after which ethane emission continued at the same level as before. When the two changes (light and temperature) were separated in time the temperature effect becomes clearly distinguishable. Ethane emission dropped when the light was switched off. Upon exposing the leaf to room temperature 1 hour later the ethane emission increased. Thereafter ethane emission declined slowly.

Among the effects resulting from a long period of chilling under light is a pigment bleaching; this could be seen visually. After a 1 day treatment the bleaching area covers between $15 \%$ and $30 \%$ of the total area, becoming larger (up to $65 \%$ ) after a 2 day long treatment.

\section{DISCUSSION}

Being a product of lipid peroxidation, emission of ethane is related to the presence of reactive oxygen species. ${ }^{5}$ The amount of reactive oxygen species is enhanced if plants are exposed to stress, ${ }^{18}$ conditions at low temperature and high light intensity. ${ }^{3}$ Indeed, several studies have shown the presence of reactive oxygen species in chilled cucumber leaves. ${ }^{19,20}$ The balance between production and scavenging of reactive oxygen species influences the extent of peroxidation and the amount of the end products like ethane and malondialdehyde.

The light response shows that photosynthesis is involved in this process. During chilling under light, the total amount of reactive oxygen species is expected to increase. ${ }^{21}$ This is not only caused by increased production, but also because the activity of scavengers (and other removal mechanisms) reduces at low temperature. Observing almost zero emission of ethane in the initial phase could be related to scavengers 
that are still highly active during this early period of treatment. At prolonged exposure total reactive oxygen produced due to chilling under light exceeds scavenging; therefore the ethane emission increases.

The postchilling burst in ethane is in agreement with earlier observations that most damage in cucumber occurs after rewarming. ${ }^{22}$ Reactive intermediates that become active at the higher temperature must play an important role therein: Since the ethane overshoot is also observed when the leaf is rewarmed in the dark, the production is decoupled from photosynthesis.

In conclusion; using a $\Delta v=2 \mathrm{CO}$ laser based photoacoustic detector, ethane evolution from chilling-sensitive cucumber leaves under various chilling treatments could be monitored in real time. The present instrument allows for fast detection necessary for postchilling events and light/ temperature response curves.

\section{ACKNOWLEDGMENTS}

The authors wish to express their thanks to C. Sikkens, L. Gerritsen, P. Claus, C. Timmer, H. Schoutissen, and J. L. M. Haerkens for their technical support, and to Dr. S. te Lintel Hekkert for his help in the construction of the system. This work has been financially supported by Stichting Porticus and the Royal Dutch Academy of Arts and Sciences.

${ }^{1}$ J. S. Boyer, Science 218, 443 (1982).

${ }^{2}$ R. R. Wise and A. W. Naylor, Plant Physiol. 83, 272 (1987).
${ }^{3}$ R. R. Wise, Photosynthesis Res. 45, 79 (1995).

${ }^{4}$ G. Oquist, D. H. Greer, and E. Ogren, in Photoinhibition, edited by D. J. Kyle, C. B. Osmond, and C. J. Arntzen (Elsevier, Amsterdam, 1987), pp. $67-87$.

${ }^{5}$ B. Halliwel and J. M. C. Gutteridge, Free Radicals in Biology and Medicine (Clarendon, Oxford, 1989).

${ }^{6}$ C. K. N. Patel, Phys. Rev. 141, 71 (1966).

${ }^{7}$ S. Bernegger and M. W. Sigrist, Infrared Phys. 30, 375 (1990).

${ }^{8}$ F. G. C. Bijnen, F. J. M. Harren, J. H. P. Hackstein, and J. Reuss, Appl. Opt. 35, 5357 (1996).

${ }^{9}$ H. Zuckermann, F. J. M. Harren, J. Reuss, and D. H. Parker, Plant Physiol. 113, 925 (1997).

${ }^{10}$ A. A. E. Martis, S. Buscher, F. Kuhnemann, and W. Urban, Instrum. Sci. Technol. 26, 177 (1998).

${ }^{11}$ H. Dahnke, J. Kahl, G. Schuler, W. Boland, W. Urban, and F. Kuhnemann, Appl. Phys. B: Lasers Opt. 70, 275 (2000).

${ }^{12}$ S. T. Persijn, R. H. Veltman, J. Oomens, F. J. M. Harren, and D. H. Parker, Appl. Spectrosc. 54, 62 (2000).

${ }^{13}$ M. Gromoll-Bohle, W. Bohle, and W. Urban, Opt. Commun. 69, 409 (1989).

${ }^{14}$ E. Bachem, E. A. Dax, T. Fink, A. Weidenfeller, M. Schneider, and W. Urban, Appl. Phys. B: Photophys. Laser Chem. 57, 185 (1993).

${ }^{15}$ I. E. Santosa, L. J. J. Laarhoven, S. te Lintel Hekkert, and F. J. M. Harren, Appl. Spectrosc. (submitted).

${ }^{16}$ P. L. Meyer and M. W. Sigrist, Rev. Sci. Instrum. 61, 1179 (1990).

${ }^{17}$ J. Oomens, H. Zuckermann, S. Persijn, D. H. Parker, and F. J. M. Harren, Appl. Phys. B: Lasers Opt. 67, 459 (1998).

${ }^{18}$ C. H. Foyer, M. Lelandais, and K. J. Kunert, Physiol. Plant. 92, 696 (1994).

${ }^{19}$ R. R. Wise and A. W. Naylor, Plant Physiol. 83, 278 (1987).

${ }^{20}$ W. Shen, K. Nada, and S. Tachibama, J. Jpn. Soc. Hort. Sci. 68, 780 (1999).

${ }^{21}$ K. Asada and M. Takahashi, in Photoinhibition, edited by D. J. Kyle, C. B. Osmond, and C. J. Arntzen (Elsevier, Amsterdam, 1987), pp. 227-287.

${ }^{22}$ S. J. Kuo and K. L. Parkin, J. Food. Sci. 54, 1488 (1989). 